\title{
Autoeficácia para dirigir, desengajamento moral e impulsividade em motoristas
}

\author{
Jocemara Ferreira Mognon - Universidade São Francisco, Itatiba, Brasil \\ Acácia Aparecida Angeli dos Santos - Universidade São Francisco, Itatiba, Brasil
}

\begin{abstract}
Resumo
O objetivo deste estudo foi verificar possíveis diferenças nos escores dos instrumentos que avaliam a autoeficácia para dirigir, o desengajamento moral e a impulsividade em razão de variáveis como sexo, faixa etária, tempo de habilitação e frequência com que se dirige, bem como analisar a predição destes construtos para envolvimento em multas e acidentes de trânsito. Participaram 500 motoristas em processo de renovação da CNH, com idades entre 23 e 78 anos, sendo 60,4\% do sexo masculino. Os instrumentos utilizados foram a Escala de Autoeficácia para Dirigir (EADir), a Escala de Justificativas de Motoristas (EJM) e a Escala de Avaliação da Impulsividade (EsAvI-A). Os resultados indicaram diferenças significativas para todas as variáveis sociodemográficas e que os construtos predizem multas e acidentes de trânsito. Esses achados contribuem para a compreensão de alguns comportamentos dos condutores e reforçam os indícios de que infrações e acidentes de trânsito são multideterminados. Palavras-chave: Autoeficácia; Trânsito; Avaliação psicológica.
\end{abstract}

Self-efficacy to drive, impulsivity and moral disengagement in drivers

\begin{abstract}
The aim of this study was to investigate possible differences in the scores of instruments that assess the efficacy to drive, impulsivity and moral disengagement because of variables such as sex, age, time of driver license and the driving frequency, as well as analyzing the prediction of these constructs for involvement in fines and traffic accidents. 500 drivers participated in the process of renewal of $\mathrm{CNH}$, aged 23-78 years, 60.4\% male. The instruments used were the Self-Efficacy Scale to Drive (EADir), Scale justifications drivers (EJM) and the Scale for Assessing Impulsivity (EsAvI-A). The results indicated significant differences for all sociodemographic variables and that the constructs predict fines and traffic accidents. These findings contribute to the understanding of some driver behavior and reinforce the evidence that violations and traffic accidents are multidetermined. Keywords: Self-efficacy; Transit; Psychological evaluation.
\end{abstract}

La eficacia de la unidad, la impulsividad y lo desenganje moral de los conductores

\begin{abstract}
Resumen
El objetivo de este estudio fue investigar las posibles diferencias en las puntuaciones de los instrumentos que evalúan la eficacia de la unidad, la impulsividad y la desenganje moral debido a variables como el sexo, la edad, el tiempo de activación y la frecuencia con la que se dirige, así como el análisis de la predicción de estos construcciones para la participación en multas y accidentes de tránsito. 500 pilotos participaron en el proceso de renovación de la $\mathrm{CNH}$, con edades entre 23-78 años, el 60,4\% hombres. Los instrumentos utilizados fueron la Escala de Autoeficacia para Conducir (EADir) Escala Justificaciones de conductores (EJM) y la Escala para la Evaluación de la Impulsividad (EsAvI-A). Los resultados indicaron diferencias significativas para todas las variables sociodemográficas y los construtos predicen multas y accidentes de tránsito. Estos resultados contribuyen a la comprensión de algunos comportamientos del conductor y refuerzan la evidencia de que las violaciónes y accidentes de tránsito multideterminadas.

Palabras clave: Auto-eficacia, Tránsito, Evaluación psicológica.
\end{abstract}

O trânsito tem se tornado um problema de saúde pública em virtude dos números e das consequências dos acidentes automobilísticos, já que dados da Organização Mundial da Saúde (OMS), do ano de 2009, indicaram que 1,3 milhão de pessoas morreram no mundo por acidentes de trânsito. Em relação ao Brasil, o Ministério da Saúde (2010) contabilizou mais de 40 mil óbitos por acidentes de trânsito e 145,9 mil pessoas, a maioria homens jovens e adultos da Região Sudeste, foram tratadas pelo Sistema Único de Saúde (SUS) em decorrência dos acidentes de trânsito, com um custo de 187 milhões de reais.
Estima-se que o fator humano seja o principal responsável, visto estar presente em cerca de $90 \%$ dos acidentes, sendo causados por erros ou violações à lei (Hoffmann, 2005; Rozestraten, 1988). As condutas que podem gerar riscos e os fenômenos psicológicos envolvidos na condução de veículos são de interesse da Psicologia do Trânsito, definida como o estudo dos comportamentos das pessoas neste contexto, bem como dos fatores humanos externos ou internos que as motivam (Rozestraten, 1988). No que se refere à avaliação psicológica pericial, a psicologia do trânsito tem como objetivo atuar de forma preventiva, buscando a 
diminuição da possibilidade dos motoristas se envolverem em situações de risco (Lamounier \& Rueda, 2005). Desde 1962 a avaliação psicológica pericial é requisito obrigatório para obtenção da Carteira Nacional de Habilitação (CNH) e desde 1953, quando o motorista exerce atividade remunerada (EAR).

Entretanto, além das habilidades tradicionalmente investigadas na avaliação pericial, as crenças desses motoristas sobre o trânsito e o respeito às normas sociais também podem ser relevantes para compreender os motivos dos acidentes de trânsito. Uma crença que precisa ser investigada é a autoavaliação dos motoristas sobre a sua capacidade para dirigir com segurança, a qual é denominada de autoeficácia para dirigir e embasada pela Teoria Social Cognitiva. Para Bandura (1997), as crenças de autoeficácia referem-se ao julgamento pessoal sobre as suas capacidades para produzir os resultados esperados em uma determinada tarefa. Vale lembrar que o construto de autoeficácia tem sido estudado em diversos contextos, como organizacional, saúde, educacional e esporte (Bandura, 1997). No entanto, Delhome e Mayer (2004) já destacavam que poucos são os estudos de autoeficácia relativos à condução veicular.

Nesse sentido, as poucas pesquisas investigando a autoeficácia para dirigir foram realizadas no exterior. $\mathrm{O}$ fator idade pode ser entendido como importante ao se avaliar a autoeficácia para dirigir, pois os resultados das pesquisas (MacDonald, 2007; Stacey \& Kendig, 1997) com motoristas com idades acima de 60 anos mostraram baixos níveis de autoeficácia, associados também com a baixa quantidade de quilômetros percorridos. Ademais, no estudo de Taubman, Ari, Mikulincer e Iram (2004), as altas pontuações em autoeficácia para dirigir foram relacionadas à condução imprudente nos motoristas jovens. Com base nos resultados dos dois estudos, pode-se afirmar que o excesso de confiança nas habilidades de dirigir nos jovens tende a contribuir com comportamentos de risco, enquanto para os motoristas idosos, há a falta de confiança em dirigir com segurança.

No estudo de Delhome e Meyer (2004), os principais resultados indicaram que os motoristas com escores baixos em autoeficácia para dirigir foram os que cometeram mais erros, quando comparados aos que apresentaram altos escores, enquanto os motoristas menos experientes na direção, mas que acreditavam muito na sua capacidade para dirigir, cometeram mais erros do que os motoristas com baixas crenças de autoeficácia. Para os autores, a autoeficácia contribui para a construção da habilidade de dirigir, sendo importante que o seu papel seja mais bem compreendido, já que é indispensável para o processo de aprendizagem, mas também é preciso entender a extensão que essas crenças podem refletir em uma avaliação irrealista e contribuir com a emissão de comportamentos de riscos. Corroborando essa ideia, Horsthuis (2011) identificou a autoeficácia como melhor preditora para o cometimento de erros na direção, lapsos e violações do que as variáveis sexo e idade.

Os comportamentos de risco e consequentes transgressões às normas de trânsito são preocupantes, visto que os condutores que não respeitam os limites de velocidade e a sinalização e não usam cinto de segurança se envolvem mais com acidentes de trânsito (Magalhães \& Loureiro, 2007). Estudos têm mostrado que não faltam aos motoristas atenuantes sociais ou motivos exculpatórios que fazem parecer que o seu próprio comportamento não seja substancialmente relevante para controlar a ocorrência de acidentes (Perfeito \& Hoffmann, 2003; Thielen, 2010).

A interpretação dos resultados de comportamentos e de julgamentos feitos nessa situação também tem sido estudada pela Teoria Social Cognitiva em referência ao fenômeno denominado de desengajamento moral. Esse construto é entendido a partir das ideologias morais criadas pelas pessoas para justificar seus comportamentos com objetivo de convencer a si mesmo e aos outros que tais atitudes ou pensamentos não são inadequados para determinada situação (Bandura, 1990).

O desengajamento moral tem sido estudado em contextos desde processos de execução penal, práticas terroristas e ações militares, degradação do meio ambiente, até ações no mundo corporativo em que há o uso de processos de produção prejudiciais à saúde humana (Azzi, 2011). No Brasil, os estudos com base na teoria do desengajamento moral são recentes e aparecem relacionados a diversas temáticas, inclusive ao trânsito, remetendo especialmente ao cometimento de infrações (Iglesias, 2002; Luiza Neto, 2009).

Dentre os resultados da pesquisa de Iglesias (2002) com 100 motoristas do Rio de Janeiro, foi identificada correlação positiva e significativa, de magnitude moderada entre o desengajamento moral e as infrações de trânsito. No mesmo sentido, o estudo de Luiza Neto (2009) com 161 policiais do Distrito Federal permitiu inferir que as justificativas morais mais recorrentes dadas pelos motoristas mascaravam o ato infracional, tornando-o menos repreensível. Ainda 
nesse mesmo estudo, foram analisados os recursos interpostos junto ao Departamento Estadual de Trânsito, sendo verificado que predominavam justificativas atribuindo a responsabilidade pela multa ao aparelho medidor, à sinalização, ao órgão de trânsito, ao policial e aos outros motoristas.

Contudo, Iglesias (2008) ressalta que pessoas pacíficas também podem cometer atos antissociais, desde que legitimadas por algum pensamento que lhe sirva como justificativa. No entanto, no trânsito, não apenas circunstâncias momentâneas explicam os comportamentos dos motoristas, já que dentre as principais variáveis preditoras de comportamento de risco no trânsito estão os traços de personalidade do condutor (Pasa, 2013).

Em acréscimo, Santos, Boff e Konflanz (2012) realizaram uma revisão de estudos internacionais que incluiu 13 artigos publicados entre os anos de 2000 a 2011, em que foram encontradas evidências de que a avaliação dos traços de personalidade facilita a identificação de motoristas com perfis de alto risco para o envolvimento em infrações e acidentes de trânsito. Um dos traços de personalidade que se mostra relevante no trânsito é a impulsividade, que se encontra diretamente relacionada com comportamentos de risco (Araújo, Malloy-Diniz \& Rocha, 2009; Ryb, Dischinger, Kufera $\&$ Read, 2006;).

A impulsividade, segundo Wickens, Toplak e Wiesenthal (2008) refere-se à busca intencional de riscos e emoções e está diretamente ligada às violações. Diferente dos dois construtos já mencionados, a impulsividade faz parte da Teoria do Traço e é definida por Pueyo (2003) como a falta de autocontrole sobre os processos emocionais e automáticos e tendência a atuar de forma rápida e sem reflexão.

Pesquisas publicadas no exterior revelaram que a impulsividade está relacionada com a percepção e comportamentos de risco no trânsito, como abuso de álcool e excesso de velocidade (Ryb e cols., 2006); erros e violações agressivas (Constantinou, Panayiotou, Konstantinou, Loutsiou-Ladd \& Kapardis, 2011); ainda, com multas e envolvimento em acidentes (González-Iglesias, Gomes-Fraguela, Romero \& Sobral, 2012). Os dados dessas pesquisas reafirmam a importância de se focalizar a impulsividade no trânsito e a relevância da sua avaliação nos comportamentos dos condutores.

No entanto, apesar dos dados empíricos dos estudos recuperados e da resolução 425/2012 do Conselho Nacional de Trânsito (CONTRAN) apontar que um dos aspectos esperados do motorista é o controle adequado da impulsividade, as pesquisas nacionais são escassas. $\mathrm{O}$ único estudo publicado que focalizou a impulsividade em motoristas foi o de Pasa (2013), em uma amostra de 158 condutores infratores e 181 não infratores da cidade de Porto Alegre. Os autores verificaram que a impulsividade, bem como comportamentos de ingerir bebida alcoólica, assumir infrações de outro condutor, solicitar que outro condutor assumisse suas infrações e a frequência com que o condutor dirige foram preditores para o cometimento de infrações no trânsito. Por outro lado, também se evidenciou que possuir mais anos de estudo representou um fator de proteção à direção segura. As outras pesquisas encontradas buscaram avaliar a personalidade de forma geral, e encontraram alguns resultados relativos especificamente à impulsividade, demonstrando que os motoristas com acidentes e vítimas apresentam maiores médias para impulsividade e que ela está associada com infrações de trânsito (Alves \& Esteves, 2004; Lamounier, 2005).

Com base em Pasa (2013), alguns aspectos sociodemográficos, como sexo, idade, escolaridade, frequência com que dirige, tempo de $\mathrm{CNH}$ e fatores relacionados ao funcionamento da personalidade, estão comumente associados à direção insegura. Assim, o objetivo deste estudo foi verificar possíveis diferenças nos escores dos instrumentos que avaliam a autoeficácia para dirigir, o desengajamento moral e a impulsividade em razão de variáveis como sexo, faixa etária, tempo de habilitação e frequência com que se dirige, bem como analisar se alguns desses construtos predizem multas e envolvimento em acidentes de trânsito.

\section{Método}

\section{Participantes}

Participaram 500 motoristas em processo de renovação de $\mathrm{CNH}$ em duas clínicas credenciadas ao DETRAN/PR da cidade de Curitiba. As idades dos participantes variaram entre 23 e 78 anos $(M=40,61$; $\mathrm{DP}=12,88), 60,4 \%(\mathrm{n}=302)$ era de sexo masculino e $88,2 \%(\mathrm{n}=441)$ com escolaridade de ensino médio a pós-graduação. O tempo de habilitação dos condutores variou de 5 a 56 anos $(\mathrm{M}=16,82 ; \mathrm{DP}=11,86), 62,2 \%$ $(\mathrm{n}=306)$ declararam não ter tido multas nos últimos 12 meses e apenas 38,8\% ( $\mathrm{n}=192)$ tiveram de uma a 10 multas no último ano. No que se refere ao envolvimento em acidentes de trânsito, verificou-se que 174 do total dos pesquisados já haviam sofrido, 102 (58,6\%) declararam que apenas um durante o tempo que possuem a $\mathrm{CNH} ; 63(36,2 \%)$, de dois a três; e apenas 9 
$(5,2 \%)$ mais de quatro acidentes. Contudo, 107 (61,5\%) relataram ter sido vítimas dos acidentes, ou seja, terceiros foram os responsabilizados pela situação. Já 38 $(21,8 \%)$ informaram terem sido responsabilizados pela ocorrência e $29(16,7 \%)$ relataram ter sofrido mais de um acidente, sendo em algum momento vítima e, em outro, responsabilizados.

\section{Instrumentos}

\section{Questionário Sociodemográfico}

Para obtenção de informações como sexo, idade, escolaridade, estado civil, rendimentos mensais, tempo de carteira de motorista e categoria da CNH. Foi também perguntada a frequência com que dirige, além do número de multas nos últimos doze meses e o envolvimento em acidentes de trânsito.

\section{Escala de Autoeficácia para Dirigir (Mognon \& Santos, no prelo)}

Tem como objetivo avaliar a crença dos motoristas em sua capacidade para dirigir veículos com segurança. Possui 28 itens distribuídos em uma escala com pontuação do tipo likert de 1 (pouco confiante) a 10 (totalmente confiante). O resultado da análise fatorial exploratória indicou estrutura unifatorial e a confiabilidade, verificada por meio do alfa de Cronbach, foi de 0,94.

Escala de Justificativas de Motoristas - EJM (Iglesias, 2002 adaptada por Luiza Neto, 2009)

O objetivo da escala é avaliar o cometimento de atos antissociais pelos motoristas e são avaliados por meio de justificativas. Foi elaborada por Clark, Iglesias e da Silva (2000, apud Iglesias, 2002) com base na Multifaceted Scale of Mechanismsof Moral Disengagement de Bandura. Os itens do instrumento original foram submetidos a um processo de tradução e retradução por um pesquisador bilíngue, adaptando-os à temática do comportamento infracional no trânsito. Inicialmente composta por 57 itens, representava cada um dos quatro esquemas de desengajamento moral. A versão final de coleta, no entanto, apontou inconsistência em 20 dos 57 itens, mantendo-se um formato de 37 itens, os quais foram avaliados por meio da análise de cinco juízes especialistas em psicologia social, ambiental e do trânsito, indicando a necessidade de efetuar alterações de ordem semântica e a exclusão de um item ambíguo.

Luiza Neto (2009) investigou as qualidades psicométricas do instrumento e os resultados indicaram uma versão final com 28 itens, sendo o primeiro fator denominado de Reconstrução da conduta (com 10 itens e $\alpha$ de 0,82$)$ - referindo-se à racionalização da conduta em uma boa ação; o segundo fator denominado de Jeitinho - possui itens referentes tanto aos mecanismos de Reconstrução da conduta como aos de Distorção do agente de ação (possui 11 itens e $\alpha$ de 0,82) - relaciona-se à atribuição de culpa ao outro pelo seu ato e racionalização da conduta; e o terceiro - predominância dos mecanismos de Distorção do agente da ação (7 itens e $\alpha 0,70)$ - refere-se a atribuição da sua culpa ao outro.

Escala de Avaliação da Impulsividade - EsAvI-A (Rueda \& Ávila-Batista, 2013)

O instrumento avalia a impulsividade e apresenta propriedades psicométricas adequadas. Possui 36 itens divididos em quatro dimensões, nomeados como: fator 1 - falta de concentração e de persistência (composto por 14 itens e $\alpha=0,87$ ) - que se refere à incapacidade que o indivíduo apresenta de manter o foco em uma determinada tarefa ou atividade por um tempo prolongado sem se dispersar, assim como dar continuidade a algo que tenha iniciado; fator 2 - controle cognitivo (composto por 9 itens e $\alpha=0,85$ ) - refere-se a quanto o indivíduo procura refletir sobre suas ações, buscando avaliá-las antes de agir ou responder aos estímulos externos ou internos; fator 3 - planejamento futuro (composto por 7 itens e $\alpha 0,78$ ) - o qual avalia a capacidade de planejar ações cujos efeitos não se restringem ao momento presente; fator 4 - audácia e temeridade (composto por 6 itens e $\alpha 0,62$ ) - refere a incapacidade de avaliar situações que possam envolver algum risco, bem como refletem a busca por sensações novas.

\section{Procedimento de coleta de dados}

Com a aprovação do Comitê de Ética em Pesquisa, a autorização do DETRAN/PR e das proprietárias das clínicas iniciou-se a coleta dos dados. Os candidatos à renovação que tiveram resultado de "apto" na avaliação de aptidão física e mental eram encaminhados, individualmente, pelo médico, a uma sala previamente preparada para a realização da pesquisa. Então, a pesquisadora se apresentava, informava que o resultado no exame médico havia sido "apto", bem como os motivos para o candidato ter sido encaminhado até a sala. Com isso, apresentava os objetivos da pesquisa e, principalmente, ressaltava que a participação era voluntária, que os dados seriam mantidos em sigilo, que os procedimentos do DETRAN e da pesquisa eram distintos e independentes e que a avaliação não era obrigatória, e 
caso não aceitassem participar não haveria nenhuma consequência no seu processo de renovação. Os condutores que aceitaram participar da pesquisa assinaram o Termo de Consentimento Livre e Esclarecido e a pesquisadora explicava a forma de realização de cada instrumento. O tempo aproximado de cada aplicação foi de 15 minutos.

\section{Procedimento de análise de dados}

Os dados foram tabulados e analisados com o software estatístico SPSS (Statistical Package for Social Sciences), versão 18.0. Depois, foram submetidos a procedimentos de estatística descritiva, sendo analisadas diferenças decorrentes de variáveis sociodemográficas com o teste t de Student, quando se compararam homens e mulheres, e com a ANOVA, para a comparação da amostra de acordo com faixas etárias, tempo de experiência do condutor e frequência com que dirige. Para a análise e regressão logística, seguiram-se alguns procedimentos padrão, como a verificação de ausência de multicolinearidade entre as variáveis por meio da correlação de Spearman, em razão da ausência do pressuposto da normalidade. O método utilizado para seleção do melhor modelo foi o forward stepwise, pelo critério de máxima verossimilhança (Likelihood Ratio - LR). A adequação do modelo de regressão logística foi verificado pelo o teste Wald e o resultado foi significativo ao nível de $5 \%(p<0,05)$, rejeitando-se a hipótese nula de que as variáveis independentes avaliadas não produzem efeito sobre as variáveis dependentes.

\section{Resultados}

Considerando os objetivos estabelecidos, primeiramente foram investigadas diferenças atribuídas à variável sexo. A Tabela 1 mostra os resultados das análises.

Os dados da Tabela 1 mostram as diferenças estatisticamente significativas na EADir, e nas três dimensões da EJM, na dimensão Audácia e temeridade e na variável envolvimento em acidentes sendo as maiores médias para os homens, enquanto, no fator Falta de concentração e persistência da EsAvI-A, as maiores médias foram para as mulheres.

Tabela 1. Análise para a variável sexo na EADir, EJM, EsAvI-A, multas e envolvimento em acidentes $(\mathrm{N}=500)$

\begin{tabular}{|c|c|c|c|c|c|c|c|}
\hline & & Sexo & $\mathrm{N}$ & Média & Desvio padrão & $t$ & $p$ \\
\hline & \multirow[t]{2}{*}{ EADIR } & $\mathrm{M}$ & 302 & 242,26 & 31,118 & \multirow[b]{2}{*}{4,042} & \multirow[t]{2}{*}{0,001} \\
\hline & & $\mathrm{F}$ & 198 & 229,69 & 37,399 & & \\
\hline \multirow{6}{*}{$\frac{\Sigma}{\mid I I}$} & \multirow[t]{2}{*}{ Reconstrução da conduta } & M & 302 & 11,78 & 3,915 & \multirow[b]{2}{*}{1,946} & 0,053 \\
\hline & & $\mathrm{F}$ & 198 & 11,13 & 3,245 & & \\
\hline & Jeitinho & M & 302 & 15,35 & 5,055 & \multirow{3}{*}{2,235} & 0,027 \\
\hline & & $\mathrm{F}$ & 198 & 14,35 & 4,840 & & \\
\hline & \multirow[t]{2}{*}{ Distorção do agente da ação } & M & 302 & 7,65 & 2,718 & & 0,019 \\
\hline & & $\mathrm{F}$ & 198 & 7,15 & 2,440 & 2,013 & \\
\hline \multirow{8}{*}{ 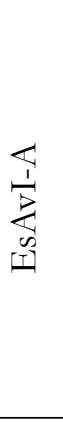 } & Falta de concentração e persistência & $\mathrm{M}$ & 302 & 21,98 & 6,077 & \multirow{3}{*}{$-3,237$} & 0,001 \\
\hline & \multirow{3}{*}{ Controle cogntivo } & $\mathrm{F}$ & 198 & 23,72 & 5,738 & & \\
\hline & & M & 302 & 29,32 & 4,801 & & 0,639 \\
\hline & & $\mathrm{F}$ & 198 & 29,12 & 4,518 & 0,476 & \\
\hline & \multirow[t]{2}{*}{ Planejamento do futuro } & M & 302 & 13,12 & 3,300 & \multirow{3}{*}{0,073} & 0,942 \\
\hline & & $\mathrm{F}$ & 198 & 13,10 & 3,082 & & \\
\hline & \multirow[t]{2}{*}{ Audácia e temeridade } & M & 302 & 13,48 & 3,439 & & 0,042 \\
\hline & & $\mathrm{F}$ & 198 & 12,84 & 3,338 & 1,962 & \\
\hline & \multirow[t]{2}{*}{ Multas } & $\mathrm{M}$ & 302 & 0,73 & 1,152 & \multirow{3}{*}{1,400} & 0,162 \\
\hline & & $\mathrm{F}$ & 198 & 0,58 & 1,221 & & \\
\hline & \multirow[t]{2}{*}{ Acidentes } & M & 302 & 0,75 & 1,644 & & 0,003 \\
\hline & & F & 198 & 0,39 & 0,703 & 2,937 & \\
\hline
\end{tabular}


Para a variável idade foram estabelecidos grupos com maior risco de acidentes de trânsito, segundo dados do Ministério da Saúde de 2010. Assim, os grupos foram divididos, compreendendo o primeiro idades entre 23 a 29 anos; o segundo, de 30 a 39 anos; o terceiro, de 40 a 49 anos e o último grupo com idades acima de 50 anos. Os resultados indicaram diferenças estatisticamente significativas nos escores da EADir $[\mathrm{F}(3,496)=5,706 ; p<0,001]$ com menor média para os com mais de 50 anos; e nas dimensões da EsAvI-A - Falta de concentração e Persistência $[\mathrm{F}(3,496)=4,106 ; p=0,006]$, Planejamento do futuro $[\mathrm{F}(3,496)=8,947 ; p=0,001]$ e Audácia e temeridade $[\mathrm{F}(3,496)=7,626 ; p=0,001]$ com maiores médias para os motoristas mais jovens, enquanto, na dimensão Controle cognitivo $[\mathrm{F}(3,496)=6,103 ; p=0,001]$, a maior média foi para os motoristas acima de 50 anos.

Quanto à variável tempo de obtenção da $\mathrm{CNH}$, julgou-se pertinente realizar a comparação considerando-se o efeito da variável idade. Foram incluídas a autoeficácia para dirigir, os fatores da EJM, as dimensões da EsAvI-A, número de multas e acidentes. Para tanto, recorreu-se à MANOVA, cujos resultados indicaram diferenças estatisticamente significativas apenas nos escores da EADir [Wilks' $\lambda=0,921, \mathrm{~F}(3,496)=5,20$, $\left.p<0,002 ; \eta^{2}=0,032\right)$. Na Figura 1 é possível verificar a separação dos grupos para tempo de $\mathrm{CNH}$ quanto às pontuações na EADir.

A Figura 1 traz os dados obtidos na EADir, visto que foi a única que apresentou diferença significativa, quando se considerou tempo de $\mathrm{CNH}$ e se controlou o efeito da idade. Os resultados indicaram que a autoeficácia para dirigir aumenta conforme aumentam os anos de obtenção da CNH.

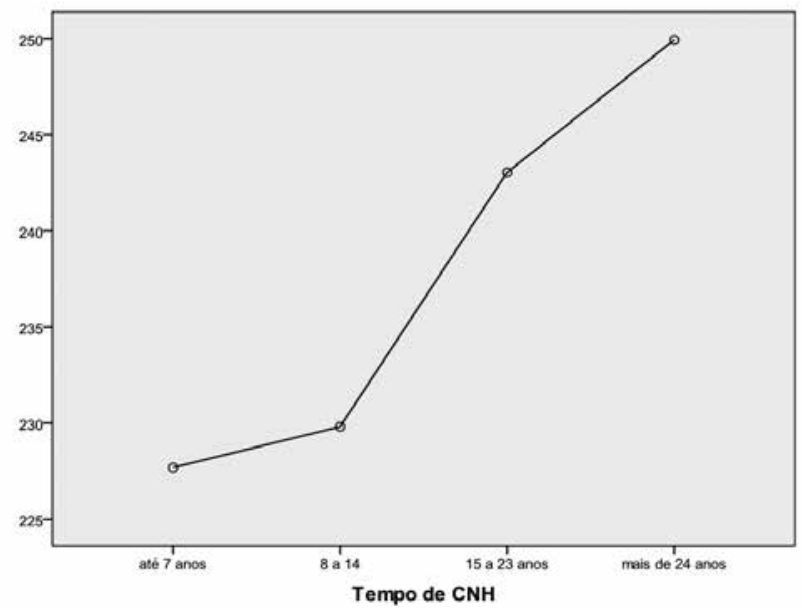

Figura 1. Tempo de CNH e pontuações na EADir
Buscou-se também avaliar diferenças para a variável frequência com que os motoristas dirigiam semanalmente e aplicou-se a ANOVA. Os resultados indicaram diferença significativa na EADir $[\mathrm{F}(2,497)=42,032 ; \quad p<0,001]$ para multas $[\mathrm{F}(2$, 497) $=8,941 ; p<0,001]$ e envolvimento em acidentes $[\mathrm{F}(2,497)=11,816 ; p<0,001]$. O post-hoc de Tukey indicou que os motoristas que dirigem uma vez ou mais por dia apresentaram escores em autoeficácia para dirigir, número de multas e envolvimento em acidentes maiores que os que dirigem uma vez por semana e este, maior que os que raramente dirigem.

Com o objetivo de compreender se os construtos de autoeficácia para dirigir (EADir), desengajamento moral (EJM) e impulsividade (EsAvI-A) predizem o número de multas nos últimos doze meses e o envolvimento em acidente de trânsito, utilizou-se a regressão logística. Os resultados indicaram que, na EADir, o modelo prediz o número de multas (OR $=1,62$; IC 95\% 1,28-2,05) e envolvimento em acidentes ( $\mathrm{OR}=1,42$; IC 95\% 1,13-1,78), enquanto, para a EJM, a dimensão Reconstrução da conduta (OR=1,29; IC 95\% 0,981,66), o envolvimento em acidentes e o fator Jeitinho na predição de multas (OR=1,33; IC 95\% 1,02-1,72). Por fim, a dimensão Falta de concentração e persistência da EsAvI-A contribui com a predição de multas $(\mathrm{OR}=1,25$; IC95\% 0,97-1,56). Os resultados indicam que pessoas que acreditam muito na sua capacidade como motorista apresentaram uma probabilidade aproximadamente $50 \%$ maior de terem multas e envolvimento em acidentes. Os motoristas que se utilizam mais de justificativas baseadas na Reconstrução da conduta têm maiores chances de envolvimento em acidentes. Já em relação ao cometimento de multas, as pessoas que julgaram utilizar justificativas baseadas no fator Jeitinho apresentaram probabilidade maior, bem como as que pontuaram mais em Falta de concentração e persistência.

\section{Discussão e Considerações finais}

O trânsito tem se configurado como um ambiente propício para investigações empíricas da psicologia, já que o número de acidentes é crescente e a causa humana (Hoffmann, 2005; Rozestraten, 1988) aparece como responsável por maior parte dessas ocorrências. Com o propósito de ampliar a compreensão sobre aspectos do fator humano, foram avaliadas as diferenças relativas às variáveis sexo, idade, tempo de habilitação e frequência com que dirige. Foi também analisado se os escores de 
medidas de autoeficácia para dirigir (EADir), de desengajamento moral (EJM) e de impulsividade (EsAvI-A) podem predizer multas e envolvimento em acidentes de trânsito.

No que se refere à variável sexo, verificou-se que os homens apresentaram médias significativamente maiores em Autoeficácia para dirigir, nos fatores Reconstrução da conduta, Jeitinho e Distorção do agente da ação da EJM, na dimensão Audácia e temeridade da EsAvI-A e na variável envolvimento em acidentes. A partir dos resultados, é possível inferir que os homens acreditam mais na sua capacidade para dirigir e se valem de mecanismos para transformar o seu ato prejudicial no trânsito em uma boa conduta, distorcendo os seus efeitos maléficos por meio de justificativas socialmente aceitas com objetivo de evitar penalidades em benefício próprio. Apresentam, também, incapacidade de avaliar as situações que envolvem risco e tendem a buscar por sensações novas, consequentemente tendem a ter maior envolvimento em acidentes de trânsito.

Há congruência desses achados com os resultados da revisão realizada por Magalhães e Loureiro (2007) e dos dados de 2010 do Ministério da Saúde, nos quais os homens integram o grupo de risco, sendo a maioria nos acidentes de trânsito. Embora não haja estudos que corroborem os dados sobre o desengajamento moral, aqui encontrados, a pesquisa de Luiza Neto (2009) identificou predomínio dos homens nas solicitações de recursos aos órgãos de trânsito contestando as multas recebidas, o que pode ser indicativo da não aceitação da ocorrência, com possível autojulgamento positivo sobre a habilidade no trânsito ou pela justificação de sua conduta ao volante. Quanto à impulsividade, González-Iglesias e cols. (2012) não encontraram diferenças significativas para a variável sexo. Mas, os resultados da presente pesquisa reforçam a necessidade de se investigar essa variável, pois além dos fatores biológicos e inatos, aspectos culturais e contextuais ligados às diferenças entre os sexos no trânsito precisam ser explorados.

No que se refere à faixa etária, foram identificadas diferenças significativas na EADir, com menor média para os motoristas da faixa etária acima de 50 anos, indicando que eles acreditam menos na sua capacidade para dirigir com segurança. Este resultado assemelha-se aos de Stacey e Kendig (1997) e McDonalds (2007), o que possibilita deduzir que, ao perceber a diminuição das capacidades cognitivas, os motoristas sintam-se menos confiantes e evitem dirigir. Mas, vale ressaltar que, quanto à idade, há dissenso na literatura, já que, no estudo de Taubman e cols. (2004), o excesso da autoconfiança na capacidade para dirigir foi relacionadas à condução imprudente nos motoristas jovens. Diante disso, estudos futuros deverão ocorrer para melhor esclarecer o papel do fator idade e dos aspectos cognitivos na autoeficácia para dirigir.

$\mathrm{Na}$ EsAvI-A, as diferenças foram significativas nas dimensões Falta de concentração e persistência, Planejamento do futuro, e Audácia e temeridade, com maiores médias para os motoristas com idades entre 23 e 29 anos. Contudo, na dimensão Controle cognitivo, a maior média foi obtida por motoristas de 50 anos ou mais. Com base na descrição do que representa cada dimensão, pode-se afirmar que os motoristas mais jovens foram os que declararam apresentar maior dificuldade para manter o foco em determinada atividade por um tempo prolongado, bem como em dar continuidade a algo que tenham iniciado. Apesar disso, declararam que planejam suas ações futuras, mas não avaliam as situações que podem envolver risco e buscam por sensações novas, enquanto os mais idosos declararam que procuram refletir sobre suas ações. Aspectos referentes à idade são importantes para compreensão dos comportamentos dos motoristas no trânsito, embora não tenham sido encontradas diferenças significativas no número de multas e de envolvimento em acidentes. Contudo, este achado, em especial, deve ser avaliado em novos estudos, já que, segundo dados de 2010 do Ministério da Saúde, os jovens entre 24 e 35 anos são os maiores envolvidos com acidentes de trânsito, e a literatura tem destacado que pessoas impulsivas apresentam mais comportamentos de riscos e obtêm mais multas (Araújo e cols., 2009; Ryb e cols., 2006) e maior envolvimento em acidentes (Alves \& Esteves, 2004; Constantinou e cols., 2011; Lamounier, 2005).

Tanto no que se refere ao tempo de obtenção da Carteira Nacional de Habilitação (CNH) como à frequência com que os motoristas dirigem, foram identificadas diferenças significativas nos escores da EADir e no número de multas e acidentes. Tais resultados revelaram que a autoeficácia para dirigir aumenta gradativamente com o tempo que se possui a $\mathrm{CNH}$, chegando a níveis bastante altos quando se tem 24 anos de habilitação. Também, quanto mais a frequência semanal que o motorista dirige mais confiante se sente na direção, o que pode contribuir, consequentemente, com maior número de multas e envolvimento em acidentes. Assim, esses resultados indicam que a autoeficácia para dirigir está atrelada à aquisição de habilidades e experiência. Com isso, pressupõe-se que ações no sentido 
de prolongar o treinamento nos centros de formação de condutores (autoescolas) podem contribuir para que os futuros condutores sintam-se mais autoeficazes para dirigir. Além disso, é importante, também, que sejam feitos estudos que busquem compreender o quanto a autoeficácia para dirigir pode contribuir para que os motoristas assumam comportamentos de risco.

Com objetivo de compreender essa última indagação, aplicou-se a regressão logística nos dados. Assim, verificou-se que os motoristas com escores altos em autoeficácia para dirigir têm maiores chances de ter multas e envolvimento em acidentes. Outros estudos já apontavam a autoeficácia para dirigir como preditora para a frequência de arriscar-se na direção e comportamentos de risco no trânsito, como violações, erros perigosos, atenção inadequada e lapsos (Horsthuis e cols., 2011; Taubman e cols., 2004). Com isso, evidenciou-se a necessidade de novos estudos nacionais, visto que estudos estrangeiros, como o de Delhome e Meyer (2004), já apontaram que a autoeficácia contribui para o aprimoramento da habilidade de dirigir, mas, também, que o excesso de confiança nesta habilidade pode levar os motoristas a superestimar o controle que podem exercer sobre as situações de condução e tornar-se uma possível ameaça para multas e acidentes. Adicionalmente, seria conveniente que investigações fossem realizadas com amostras ampliadas e diversificadas, preferencialmente recorrendo a outras estratégias, como o uso de simuladores de direção, a fim de verificar a autopercepção do motorista e compará-la com dados reais de como ele dirige.

Os resultados da análise de regressão indicaram ainda maior probabilidade de envolvimento em acidentes também para os motoristas que utilizam o esquema "Reconstrução da conduta". O uso desse esquema visa transformar o ato prejudicial em uma boa conduta, podendo ser utilizado pelos motoristas para minimizar o efeito negativo da ação transgressora sobre si mesmo. No estudo de Iglesias (2002) já havia sido apurada correlação de magnitude moderada entre esse mesmo fator com infrações de trânsito. Igualmente, Luiza Neto (2009) identificou o uso recorrente desse esquema na justificação às infrações de trânsito. Ressalta-se que não houve como comparar com os resultados encontrados no que se refere ao envolvimento em acidentes, já que essa variável não foi contemplada nas pesquisas citadas, que focalizaram apenas as multas. No entanto, parece que essas variáveis estão diretamente relacionadas entre si, como verificado no estudo de Constantinou e cols. (2011). Mas são necessários novos estudos, já que as justificativas morais fornecidas pelos motoristas refletem as crenças que têm sobre o trânsito, as normas e os outros motoristas, que podem sofrer interferência da cultura e do contexto no qual estão inseridos.

No que diz respeito ao fator "Jeitinho", verificou-se que os motoristas que mais recorreram a esse esquema, que é a busca por resolução de problemas por meio da influência social, combinando-a com truques de esperteza e quebra das regras sociais, apresentam maiores chances de ter multas. Luiza Neto (2009) também identificou que esse esquema está presente nas justificativas dos motoristas tanto no momento das abordagens dos policiais como nos recursos de multas interpostos ao DETRAN, quando são usados argumentos que variam desde a sensibilização da polícia e agentes de trânsito, invocação de prestígio até a ameaça.

Para as dimensões da Escala de Avaliação da Impulsividade (EsAvI-A) somente foi encontrada predição para a dimensão "Falta de concentração e persistência" com multas, indicando que as pessoas com dificuldade para manter o foco por tempo prolongado em algo têm maiores chances de cometer multas. Nesse caso, a distração parece estar mais implicada com o erro do que com a imprudência. Esse resultado é em parte esperado, já que a atenção é essencial no contexto do trânsito, tanto que a avaliação deste construto é obrigatória nos processos de avaliação psicológica pericial. Mas o resultado encontrado na pesquisa não identificou as outras características da impulsividade avaliadas pela EsAvI-A como preditoras para o envolvimento em acidentes de trânsito, diferindo do estudo de Pasa (2013). Todavia, Araújo e cols. (2009) já haviam concluído, em seu estudo de revisão da literatura, que a relação entre impulsividade e acidente de trânsito é controversa. Assim, dada a importância que esse construto representa na avaliação pericial no trânsito, esses achados merecem ser retomados em estudos futuros.

Não se pode deixar de apontar as limitações deste estudo. A primeira refere-se ao uso de instrumentos de autorrelato, bem como ao uso para apuração do envolvimento em multas e acidentes, visto que os resultados podem não corresponder à realidade, pois a desejabilidade social estava muito presente, dado o cenário da pesquisa, em uma clínica de avaliação pericial para o trânsito e em processo de renovação da $\mathrm{CNH}$. Embora tenham sido tomados cuidados no momento da abordagem para a participação da pesquisa, é importante que haja cautela na interpretação dos dados.

Conclui-se que os fatores envolvidos na ocorrência de comportamentos de risco que resultam em multas e acidentes são multideterminados. Apesar disso, espera-se que os resultados encontrados nesta pesquisa 
possam contribuir com o avanço da psicologia do trânsito e instiguem pesquisadores e profissionais interessados pelo comportamento humano neste contexto à realização de novos estudos. Pois, para a psicologia do trânsito, é importante que sejam identificadas as características humanas associadas aos comportamentos dos motoristas que poderão ser consideradas nos processos de avaliação pericial ou, ainda, ser abordadas no processo de educação de motoristas e na elaboração de campanhas de trânsito.

\section{Referências}

Alves, I. C. B., \& Esteves, C. (2004). O teste Palográfico na Avaliação da Personalidade. São Paulo: Vetor.

Araújo, M. M., Malloy-Diniz, L. F., \& Rocha, F. L. (2009). Impulsividade e acidentes de trânsito. Revista de Psiquiatria Clínica, 36(2), 60-68.

Azzi, R. G. (2011). Desengajamento moral na perspectiva da Teoria Social Cognitiva. Psicologia Ciência e Profissão, 31(2), 208-21.

Bandura, A. (1990). Selective activation and disengagement of moral control. Journal of Social Issues, 46, 27-46.

Bandura, A. (1997). Selfefficacy: the exercise of control. New York: W. H. Freman and Company.

Conselho Nacional de Trânsito (2012). Resolução CNT no 425/2012 de 27 de novembro de 2012. Disponível em: http://www.denatran. gov.br/download/Resoluções/(resolu http:// www.denatran.gov.br/download/Resolucoes / (Resolu\%C3\%A7\%C3\%A3o\%20425.-1).pdf.

Constantinou, E., Panayiotou, G., Konstantinou, N., Loutsiou-Lad, A., \& Kapardis, A. (2011). Risky and aggressive driving in young adults: personality matters. Accident Analysis and Prevention, 43, 1323-1331.

Delhome, P., \& Meyer, T. (2004). Risk taking and selfefficacy among young male drivers: self-efficacy and changing task demands. Em T. Rothengatter \& R. D. Huguenir (Eds.), Traffic \& Transport Psychology (pp. 135-146). Elsevier Science.

González-Iglesias, B., Gomes-Fraguela, J. A., Romero, E., \& Sobral, J. (2012). The effects of impulsiveness and alcohol abuse on traffic code violation. Journal of Psychology Applied to Legal Context, 4(1), $1-16$.
Hoffmann, M. H. (2005). Comportamento do condutor e fenômenos psicológicos. Psicologia: Pesquisa e Trânsito, 1(1), 17-24.

Horsthuis, S. M. G. M. (2011). De bijdrage van demografische en psychologische determinanten aan riskant rijgedrag door jonge en oudere automobilisten. (Tese de Doutorado), University of Twente Student Theses. Disponível em http://essay.utwente.nl/61050.

Iglesias, F. (2002). Desengajamento moral: um estudo com infrações de trânsito. (Dissertação de Mestrado), Universidade Federal do Rio de Janeiro (UFRJ). Rio de Janeiro, RJ.

Iglesias, F. (2008). Desengajamento moral. Em A. Bandura, R. G. Azzi, \& S. Polydoro (Eds.), Teoria social cognitiva: conceitos básicos (pp. 165-176). Porto Alegre: Artes Médicas.

Lamounier, R. (2005). O Rorschach e a avaliação de motoristas: evidências de validade. (Dissertação de Mestrado), Universidade São Francisco. Itatiba, SP.

Lamounier, R., \& Rueda, F. J. M. (2005). Avaliação psicológica no trânsito: perspectiva dos motoristas. Psic - Revista de Psicologia da Vetor Editora, 6,(1), 35-42.

Luiza Neto, I. (2009). Justificativas de motoristas para infrações de trânsito: esboçando um modelo. (Dissertação de Mestrado), Universidade de Brasilia (Unb). Brasília, DF.

MacDonalds, L. (2007). Relationship of driving comfort to perceived and objective driving abilities and future driving behaviour. (Tese de Doutorado), Universidade de Waterloo, Ontário, Canadá.

Magalhães, S. H. T., \& Loureiro, S. R. (2007). Acidentes de trânsito e variáveis psicossociais - Uma revisão da literatura. Medicina, 40(3), 345-351.

Ministério da Saúde (2010). Dados sobre vítimas fatais no trânsito. Disponível em http://vias-seguras.com/ os_acidentes_do_ministerio_da_saude.

Mognon, J. F., \& Santos, A. A. A. (No prelo). Construção e estudos psicométricos da Escala de Autoeficácia para Dirigir (EADir).

Organização Mundial da Saúde. (2009). Informe sobre prevención la situasión mundial de la seguridad via: es hora de pasar a la acción. Ginebra: Organización Mundial de la Salud. Disponível em: http:/ / whqlibdoc.who. int/hq/2009/WHO_NMH_VIP_09.01_spa.pdf. 
Pasa, G. G. (2013). Impulsividade, busca de sensações e comportamentos de risco no trânsito: um estudo comparativo entre condutores infratores e não infratores. (Dissertação de Mestrado), Universidade Federal do Rio Grande do Sul. Porto Alegre, RS.

Perfeito, J., \& Hoffmann, M. H. (2003). Marketing social e circulação humana. Em: M. H. Hoffmann, R. M. Cruz, J. C. Alchieri (Eds.), Comportamento Humano no Trânsito (pp. 77-101). São Paulo: Casa do Psicólogo.

Pueyo, A. A. (2003). Evaluacion de la impulsividady riesgo en el uso de armas de fuego en policias y fuerzas de seguridad. Disponível em: www.raco.cat/index.php/RCSP/ article/view/130953/180719.

Rozestraten, R. J. A. (1988). Psicologia do trânsito: conceitos e processos básicos. São Paulo: EPU.

Rueda, F. J. M., \& Ávila-Batista, A. C. (2013). Escala de Avaliação da Impulsividade - EsAvI. Manual. São Paulo: Vetor.

Ryb, G. E., Dischinger, P. C., Kufera, J. A., \& Read, K. M. (2006). Risk perception and impulsivity: association with risky behaviors and substance abuse disorders. Accident Analysis and Prevention, 38(3), 567-573.
Santos, P. L., Boff, R. M., \& Konflanz, S. S. (2012). Relevância da avaliação obrigatória de traços de personalidade em motoristas. Psicologia: Teoria e Prática, 14(3), 101-110.

Stacey, B., \& Kendig H. (1997). Driving, cessation of driving, and transport safety issues among older people. Health Promotion Journal of Australia, 7, 175-179.

Taubman, O., Ari, B., Mikulincer, M., \& Iram, A. (2004). A multi-factorial framework for understanding reckless driving appraisal indicators and perceived environmental determinants. Transportation Reseach Part, 7, 333-349.

Thielen, I. P. (2010). O que pensam e como agem os motoristas. Em R. C. Caruso (Ed.), O automóvel. O planejamento urbano e a crise das cidades (pp. 107-118). Florianópolis: Ofício.

Wickens, C. M., Toplak. M. E., \& Wiesenthal. D. L. (2008). Cognitive failures as predictors of driving errors, lapses, and violations. Accidental Analise Prevision, 40(3),1223-1233.

Recebido em: 09/08/2013

Reformulado em: 10/12/2013

Aprovado em: 03/02/2014

Nota das autoras:

Este artigo se deu com base na dissertação de mestrado da primeira autora intitulada "Estudos para construção da Escala de Autoeficácia para dirigir (EADir)", e as autoras agradecem à CAPES pelo financiamento da pesquisa.

Sobre as autoras:

Jocemara Ferreira Mognon é psicóloga, mestre e doutoranda em Psicologia na área de concentração Avaliação Psicológica na Universidade São Francisco-Itatiba/SP e bolsista CAPES.

Acácia Aparecida Angeli dos Santos é Psicóloga, doutora em Psicologia Escolar e Desenvolvimento Humano pela USP e docente da Graduação e do Programa de Pós-Gradução Stricto Sensu em Psicologia da Universidade São Francisco -Itatiba/SP.

Contato com as autoras:

Dra. Acácia A. Angeli dos Santos - Universidade São Francisco - Programa de Pós-Graduação em Psicologia - Rua Alexandre Rodrigues Barbosa, n. 45

CEP: 13251-040. Itatiba/SP.

E-mail: acacia.angeli@gmail.com 